\title{
Evaluation of serum copper and iron levels among oral submucous fibrosis patients
}

\author{
Jyothi Tadakamadla ${ }^{1}$, Santhosh Kumar ${ }^{2}$, Mamatha GP ${ }^{3}$
}

\author{
${ }^{1}$ MDS Department of oral medicine and radiology, Vishnu Dental College, Bhimavaram, Andhra pradesh, 534202 India \\ ${ }^{2}$ MDS Department of preventive and community dentistry, Vishnu Dental College, Bhimavaram, Andhra pradesh, 534202 \\ India \\ ${ }^{3}$ MDS Department of oral medicine and radiology, College of Dental Sciences, Davangere, Karnataka, 577004 India \\ Department of oral medicine and radiology, Darshan Dental College and Hospital, Udaipur,Rajasthan, 577004 India
}

Correspondence:

Department of oral medicine and radiology,

Vishnu Dental College,

Bhimavaram, Andhra pradesh, India. 534202

docjyotia@yahoo.co.in

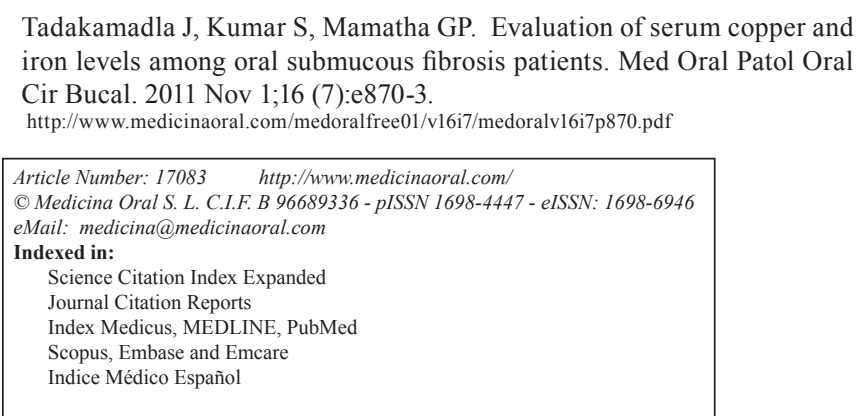

\begin{abstract}
Objective: To estimate and compare the levels of serum copper and iron among subjects with oral submucous fibrosis (OSMF) of different clinical stages and healthy controls.

Study Design: Study sample comprised of 50 patients clinically diagnosed with OSMF and 50 healthy controls who were matched for age and gender. OSMF patients were categorised by clinical staging. Serum estimation of copper and iron was done using atomic absorbtion spectrophotometry.

Results: Mean copper and iron level differed significantly $(\mathrm{p}<0.000)$ between the patients and controls with patients exhibiting higher copper (134.1 \pm 20.16$)$ and lower iron (114.78 \pm 23.47$)$ levels in contrast to controls who presented lower copper (114.8 \pm 12.36$)$ and higher iron (130.86 \pm 31.01$)$ levels in serum. There was a definite trend as $(\mathrm{P}<0.0001)$ with cases having the lesion in faucial bands (1st stage) exhibiting the lowest serum copper and those in stage 3 (faucial, labial and buccal bands) presenting the highest copper levels in serum.

Conclusions: Copper level increased and iron level decreased in study group in comparison to healthy controls. Copper level increased as clinical stage of oral submucous fibrosis increased.
\end{abstract}

Key words: Oral submucous fibrosis, serum iron, serum copper, clinical staging. 


\section{Introduction}

Oral submucous fibrosis (OSMF) is a chronic disease of the oral cavity, which is characterized by an epithelial and subepithelial inflammatory reaction followed by fibroelastic changes in the submucosa. (1)

The disease is most commonly seen in people of south Asian countries or in south Asian immigrants to other parts of the world. (2)

Clinically, patients suffer from gradual, progressive alterations in oral mucosa resulting in compromised mouth opening to various degrees. (3)

It is now evident that there exists a dose dependent relationship between oral submucous fibrosis and both frequency and duration of chewing areca nut (4) which is a common habit in south and southeast Asia. (5)

Presently, it is a well recognized, potentially premalignant condition with malignant potential and therefore a cause of concern for oral health care professionals. Malignant transformation rates as high as $7.6 \%$ have been reported from the Indian subcontinent over a 17 year period. (6) In the search for possible causes of malignancies on the one hand, and the need for a modality affording early diagnosis and follow up on the other, attention was paid to the role played by trace elements in malignancies. (7)

Among many trace elements, copper and iron are required for the functioning of numerous enzymes and therefore it is reasonable to assume that variation in serum level of these biochemical markers may be associated with the pathogenesis of oral cancer and precancerous states. (8)

Iron has been recognized as an important element for maturation of epithelium and it is well documented that iron deficiency is associated with epithelial abnormalities in addition to malignancies like post cricoid carcinoma and tumours of the pharynx and mouth. (9)

Thus biochemical alterations of copper and iron concentrations in the serum of pre malignant patients can help not only in the early diagnosis, appropriate treatment but also as an indicator for prognosis.

It has been postulated that altered serum copper and iron levels are observed among OSMF patients. Thus the present study aimed to estimate and compare the levels of serum copper and iron among subjects with oral submucuous fibrosis of different clinical stages and healthy controls.

\section{Material and Methods}

Study sample comprised of 50 patients clinically diagnosed with OSMF and 50 healthy controls who were matched for age and gender. Patients attending the outpatient department of Darshan Dental College and Hospital, Udaipur were recruited in the study.

Ethical clearance was taken from the Ethical Committee, Darshan Dental College and Hospital and written informed consent was obtained from all the subjects. Subjects suffering from chronic systemic illness and those consuming areca nut (in control group) were excluded. Inclusion criteria comprised subjects diagnosed with OSMF (in the study group) and subjects willing to provide written consent.

The staging of the OSMF was done according to the criteria of clinical grading by Haider SM et al. Clinical staging was done depending on topography and extent of distribution of bands. Stage 1 subjects had faucial bands while those in stage 2 presented faucial and buccal bands and among individuals in stage 3, faucial, buccal and labial bands were involved. (10)

Ten $\mathrm{ml}$ of blood was drawn intravenously and was centrifuged at $1000-1500$ RPM for 15 minutes. Subsequently, $5 \mathrm{ml}$ of serum was collected which was analyzed for copper and iron with atomic absorbtion spectrophotometry in addition to haematological evaluation. Haemoglobin was assessed by Sahli's method and erythrocytic sedimentation rate (ESR) was calculated by Westergren's method.

Data was entered in Microsoft Excel and analyzed using Statistical Package for Social Sciences (SPSS 15.0, Chicago., IL). Means and standard deviations were calculated for serum copper and iron levels in study and control subjects.

Independent samples ' $t$ ' test was used to compare the mean values of serum iron and copper between the study subjects and control group while one way analysis of variance (ANOVA) was used to assess the significance in difference between the mean copper and iron levels based on the staging of OSMF.

Step wise linear regression analysis was executed to assess the influence of various independent variables (age, gender, hemoglobin, ESR, serum copper and iron levels) on the dependent variable (study or control group)

\section{Results}

In the present study, the youngest patient was 18 years of age while the oldest being 60 years. Among 50 patients in both the study and control groups, 45 (90\%) were males and $5(10 \%)$ were females. It is evident from (Table 1) that mean copper and iron level differed significantly $(\mathrm{p}<0.05)$ between the patients and controls with patients exhibiting higher copper (134.1 \pm 20.16$)$ and lower iron (114.78 \pm 23.47$)$ levels in contrast to controls who presented lower copper $(114.8 \pm 12.36)$ and higher iron (130.86 \pm 31.01$)$ levels in serum.

One way ANOVA revealed a statistically significant difference in mean serum copper levels among patients in various clinical stages of OSMF. There was a definite trend as $(\mathrm{P}<0.0001)$ shown in (Table 2$)$ with cases having the lesion in faucial bands ( $1^{\text {st }}$ stage) exhibiting the lowest serum copper and those in stage 3 (faucial, labial and buccal bands) presenting the highest copper levels 
Table 1. Mean serum copper and iron concentrations $(\mu \mathrm{g} / 100 \mathrm{ml})$ in study group and control group .

\begin{tabular}{|l|c|c|c|c|}
\hline \multirow{2}{*}{ Copper } & Group & Mean & $\begin{array}{c}\text { Standard } \\
\text { Deviation }\end{array}$ & Significance \\
\cline { 2 - 4 } & Study & 134.10 & 20.16 & 0.005 \\
\hline \multirow{2}{*}{ Iron } & Control & 114.84 & 12.36 & \\
\cline { 2 - 4 } & Study & 114.78 & 23.47 & \multirow{2}{*}{0.019} \\
\cline { 2 - 4 } & Control & 130.86 & 31.01 & \multirow{2}{*}{} \\
\hline
\end{tabular}

Independent samples't' test.

Table 2. Copper and iron concentration $(\mu \mathrm{g} / 100 \mathrm{ml})$ in serum of OSMF patients in relation to clinical staging.

\begin{tabular}{|c|c|c|c|c|}
\hline & $\begin{array}{c}\text { Clinical } \\
\text { staging }\end{array}$ & $\mathbf{n}$ & Mean & $\begin{array}{c}\text { Standard } \\
\text { Deviation }\end{array}$ \\
\hline \multirow{4}{*}{ Copper* } & Stage 1 & 10 & 110.37 & 14.22 \\
\cline { 2 - 5 } & Stage 2 & 32 & 134.81 & 14.23 \\
\cline { 2 - 5 } & Stage 3 & 8 & 160.95 & 7.66 \\
\cline { 2 - 5 } & Total & 50 & 134.10 & 20.16 \\
\hline \multirow{4}{*}{ Iron } & Stage 1 & 10 & 119.58 & 16.18 \\
\cline { 2 - 5 } & Stage 2 & 32 & 115.40 & 24.66 \\
\cline { 2 - 5 } & Stage 3 & 8 & 106.27 & 26.65 \\
\cline { 2 - 5 } & Total & 50 & 114.78 & 23.47 \\
\hline
\end{tabular}

One way ANOVA. *p $<0.0001$.

Table 3. Step wise multiple linear regression analysis with age, gender, hemoglobin, ESR, serum Copper and Iron levels as independent variables and groups (patients and controls) as dependent variable.

\begin{tabular}{|c|c|c|cc|}
\hline Model & R & $\begin{array}{c}\text { R } \\
\text { Square }\end{array}$ & $\begin{array}{c}\text { Adjusted } \\
\text { R Square }\end{array}$ & $\begin{array}{c}\text { Std. Error } \\
\text { of Estimate }\end{array}$ \\
\hline 1 & $0.503^{\mathrm{a}}$ & 0.253 & 0.245 & 0.437 \\
2 & $0.647^{\mathrm{b}}$ & 0.419 & 0.406 & 0.387 \\
\hline
\end{tabular}

a Predictors: (Constant), Serum Copper level. b Predictors: (Constant), Serum Copper level, Haemoglobin level. in serum. However, there was decrease in serum iron concentration as clinical stage increased but the difference observed was not statistically insignificant.

Step wise multiple linear regression analysis was executed to assess the influence of age, gender, hemoglobin, ESR, serum copper and iron levels in predicting cases and controls. It is apparent from (Table 3) that serum copper and hemoglobin levels were the only significant variables. The first best predictor was serum copper level which exerted an influence of $25.3 \%$ whereas serum copper and hemoglobin levels together exerted an influence of $41.9 \%$.

\section{Discussion}

Among many trace elements associated with OSMF, role of copper and iron have been extensively studied and have been the subject of a multitude of investigations.

In the present study, functional grading was not considered for staging of OSMF as it is based on the degree of mouth opening which is also dependent on many other factors like cheek flexibility, pain during opening, ulcers, vesicles, burning sensation and also psychological factors.

It was observed that mean serum copper level was significantly high in study group than in control group. In accordance with our findings, many past studies have observed raised copper level in the sera of patients with oral premalignant and malignant lesions. $(8,11)$

However, Trivedy et al. (12) observed that serum copper remained normal in OSMF patients in contrast to the present study; this difference could be attributed to the small sample size and absence of a control group in their study.

Though the definite reason for increase in serum copper in premalignancies and malignancies is not known, it might be due to increased production of copper-containing ceruloplasmin by liver as an inflammatory response or due to decrease in catabolism of the serum ceruloplasmin. (13)

It was noticed that all the subjects in the study group had the history of using areca nut and high levels of copper in areca nut plays an initiating role in stimulation of fibrogenesis. (14)

Furthermore, a definite trend was observed with gradual increase in serum copper level as the clinical stage of OSMF increased. Thus, there could be a direct relation between serum copper and extent of fibrosis.

Mean serum iron concentration in study subjects was lower than the control group. Anuradha and Devi have suggested that decreased iron levels in oral submucous fibrosis patients might be due to utilization of iron in collagen synthesis. (15)

Furthermore, lack of iron in the tissues results in decreased vascularity which facilitates percolation of 
arecoline. In vitro studies on human fibroblasts observed that arecoline causes increased fibroblastic proliferation and collagen formation which is a hallmark of OSMF. (4)

Nevertheless, the study is not free of limitations. The findings of the present study could not be generalized to all the OSMF patients because of the regional and cultural variation that occurs within and between the countries.

The potential strong points of the study are that, equal number of cases and controls were included following stringent inclusion and exclusion criteria where subjects using areca nut were excluded from controls. Besides, Atomic Absorption spectro photometry was used to analyze the elements which is more accurate in elemental analysis than traditional calorimetry method. Furthermore, in the present study the serum copper and iron levels were observed in relation to clinical staging.

It can be concluded from the present study that serum copper and iron levels could be used as a potential prognostic and diagnostic markers in OSMF patients. However, as there are controversial reports on the association of OSMF and these trace elements future studies are anticipated on a larger heterogeneous population to confirm the hypothesis.

\section{References}

References with links to Crossref - DOI

1. Mehrotra R, Pandya S, Chaudhary AK, Singh HP, Jaiswal RK, Singh M, et al. Lipid profile in oral submucous fibrosis. Lipids Health Dis. 2009;8:29.

2. Shin YN, Liu CJ, Chang KW, Lee YJ, Liu HF. Association of CTLA-4 gene polymorphism with oral submucous fibrosis in Taiwan. J Oral Pathol Med. 2004;33:200-3.

3. Ceena DE, Bastian TS, Ashok L, Annigeri RG. Comparative study of clinicofunctional staging of oral submucous fibrosis with qualitative analysis of collagen fibers under polarizing microscopy. Indian J Dent Res. 2009;20:271-6.

4. Tilakaratne WM, Klinikowski MF, Saku T, Peters TJ, Warnakulasuriya S. Oral submucous fibrosis: review on aetiology and pathogenesis. Oral Oncol. 2006;42:561-8.

5. Zhang X, Li C, Liao Q, Reichart PA. Areca chewing in Xiangtan, Hunan province, China: interviews with chewers. J Oral Pathol Med. 2008;37:423-9.

6. Kiran Kumar K, Saraswathi TR, Ranganathan K, Uma Devi M, Elizabeth J. Oral submucous fibrosis: a clinico-histopathological study in Chennai. Indian J Dent Res. 2007;18:106-11.

7. Margalioth EJ, Schenker JG, Chevion M. Copper and zinc levels in normal and malignant tissues. Cancer. 1983;52:868-72.

8. Khanna SS, Karjodkar FR. Circulating immune complexes and trace elements (Copper, Iron and Selenium) as markers in oral precancer and cancer : a randomised, controlled clinical trial. Head Face Med. 2006;2:33.

9. Prime SS, MacDonald DG, Rennie JS. The effect of iron deficiency on experimental oral carcinogenesis in the rat. $\mathrm{Br} \mathrm{J}$ Cancer. 1983;47:413-8.

10. Haider SM, Merchant AT, Fikree FF, Rahbar MH. Clinical and functional staging of oral submucous fibrosis. Br J Oral Maxillofac Surg. 2000;38:12-5.

11. Jayadeep A, Raveendran Pillai K, Kannan S, Nalinakumari KR, Mathew B, Krishnan Nair M, et al. Serum levels of copper, zinc, iron and ceruplasmin in oral leukoplakia and squamous cell carcinoma. $\mathrm{J}$ Exp Clin Cancer Res. 1997;16:295-300.
12. Trivedy CR, Warnakulasuriya KA, Peters TJ, Senkus R, Hazarey VK, Johnson NW. Raised tissue copper levels in oral submucous fibrosis. J Oral Pathol Med. 2000;29:241-8.

13. Coates RJ, Weiss NS, Daling JR, Rettmer RL, Warnick GR. Cancer risk in relation to serum copper levels. Cancer Res. 1989;49:4353-6. 14. Trivedy C, Baldwin D, Warnakulasuriya S, Johnson N, Peters T. Copper content in Areca catechu (betel nut) products and oral submucous fibrosis. Lancet. 1997;349:1447.

15. Anuradha CD, Devi CS. Serum protein, ascorbic acid \& iron \& tissue collagen in oral submucous fibrosis--a preliminary study. Indian J Med Res. 1993;98:147-51. 